\title{
Technology and the North-South division of labour
}

\section{Juan F. Rada}

\section{Technology and development}

Concern about technology from the point of view of development studies has been growing consistently since it was recognised that control of technology has often led to the control of development, the definition of its aims, and the determination of its pace. The debate has, more often than not, been unduly concentrated in three broad areas. The first has been the characteristics of the technologies to be used, especially, to ensure that choices correspond to development aims and the economic and skill endowment of a given country or region. Second has been the mechanism of transfer of technology (licensing agreements, use of patents, trade secrets and so on) aimed principally at improving the conditions of the transfer of technology for developing countries (eg Code of Conduct). The third element has been the development of science and technology policies to upgrade the technical infrastructure and to encourage innovation in developing countries.

This is by no means a comprehensive listing of all the intricacies in technology-development debates. Its purpose is mainly to highlight the absence of consideration given to two equally important elements. The first is the dynamism of technical change, which although commonly recognised, is seldom assimilated with all its consequences into the debate. Technology, whether for materials, products, processes, clerical work or communications is a constantly moving target, so that the initial choice of technology is only the beginning of a process of assimilation, up-grading, and finally, innovation. However in most planning processes technology is often regarded as given, with little emphasis placed on trying to forecast how technological change might alter export or import performance, industries and raw materials. Whilst forecasting these developments remains more a craft than a science, this does not constitute an excuse for avoiding some form of indicative assessment of technological change.

The above point is closely linked to a second, increasingly important area of development research, namely the effects of technological change on the international division of labour. In other words, how do dynamic technological developments affect comparative advantage and thus development and industrialisation prospects in particular countries or regions. This phenomenon is by no means a new one, although surprisingly little attention has been paid to it. For example, history tells us that technological advances in textile manufacturing changed the international division of labour for textiles. By the $1830 \mathrm{~s}$, the price of yarn was perhaps one twentieth of what it had been 50 years earlier, and the cheapest Hindu labour could not compete in either quality or quantity with Lancashire's mules and throstles [Landes 1976:42]. Similarly, the commercialisation of the HaberBosh nitrogen fixation process in the 1920 s did away with one of Chile's most important sources of external revenue, the exploitation of natural nitrate. At one point, Chile supplied at least two-thirds of the world's nitrate requirements and the tax on exports was 80 per cent of Chile's total revenue.

The historical listing of such technological developments and their effects on the international division of labour takes us to several countries and continents and includes, among other things, the substitution of natural by artificial processes in the production of rubber (which has in fact rebounded due to increased oil prices and performance requirements), fibres, colorants, certain minerals and the current tendency of partially substituting alternative energy sources for oil. Most of these are based on high, capital intensive technology.

In a more speculative vein, and looking at the future rather than the past, several questions could be posed in the light of current and imminent technological change:

-widespread experiments (and even some pilot plants) are underway to produce industrial glucose and sweeteners out of cellulose through the use of genetically engineered micro-organisms. If these experiments prove to be commercially viable, what will be the effect on sugar demand and prices, and on the revenues of sugar producers?

- Copper has been substituted in a number of applications in the past, such as by aluminium for power transmission. It is now facing further substitution in other areas, such as by fibre optics in the field of telecommunications. This is not going to be a sudden development but an evolutionary one, over a period of years. Will this affect the aggregate demand for copper and eventually its price? 
The first example deals with biotechnology, or more specifically, with the latest developments in genetic engineering whose consequences for the international division of labour remain largely unexplored. The time horizon for commercial developments are commonly acknowledged to be between five (some new pharmaceutical products) to 20 years (applications for mining processes) although some products are already available [Congress of the United States, Office of Technology Assessment 1981].

The second deals with substitution of materials, where considerable research has already been done. But the prospects for new human-engineering materials which are presently used for sophisticated applications make an increase in the rate of this research likely.

This interaction between technological change and the international division of labour does not only affect the North-South division of labour, but also that among developed countries. A classical and often quoted example has been the substitution of precision engineering by electronic components in the watch/clock industry, which has led to the transfer of a substantial part of the industry from the traditional producer, Switzerland, to Japan and the USA. Today, Japan is the biggest watch/clock producer in the world. Of additional interest in this case is that these changes in product, which inevitably lead to changes in processes, also forced a shift in the supplies of materials, sales force and marketing structure. The bulk of watches/clocks left the specialised shops to find new outlets in supermarkets and general stores.

\section{Development models}

The complexity of the interaction between technology and the international division of labour makes it difficult to generalise about trends. Indeed a number of theories have been developed from several points of view, including the product-process cycle and factor intensity (ie labour-intensity vs capital intensity) explanations. Out of these two sets of theories a 'model' of the international division of labour has evolved. Put simply, this 'model' assumes that developing countries will develop and industrialise through the transfer of production of simpler and labour intensive products to them, while advanced countries will move up-market through more $\mathrm{R}$ and $\mathrm{D}$ and knowledge-intensive production. This view is implicit in the basic assumptions of the New International Economic Order, the Third World industrialisation programme of UN agencies such as UNIDO, and the Brandt Report.

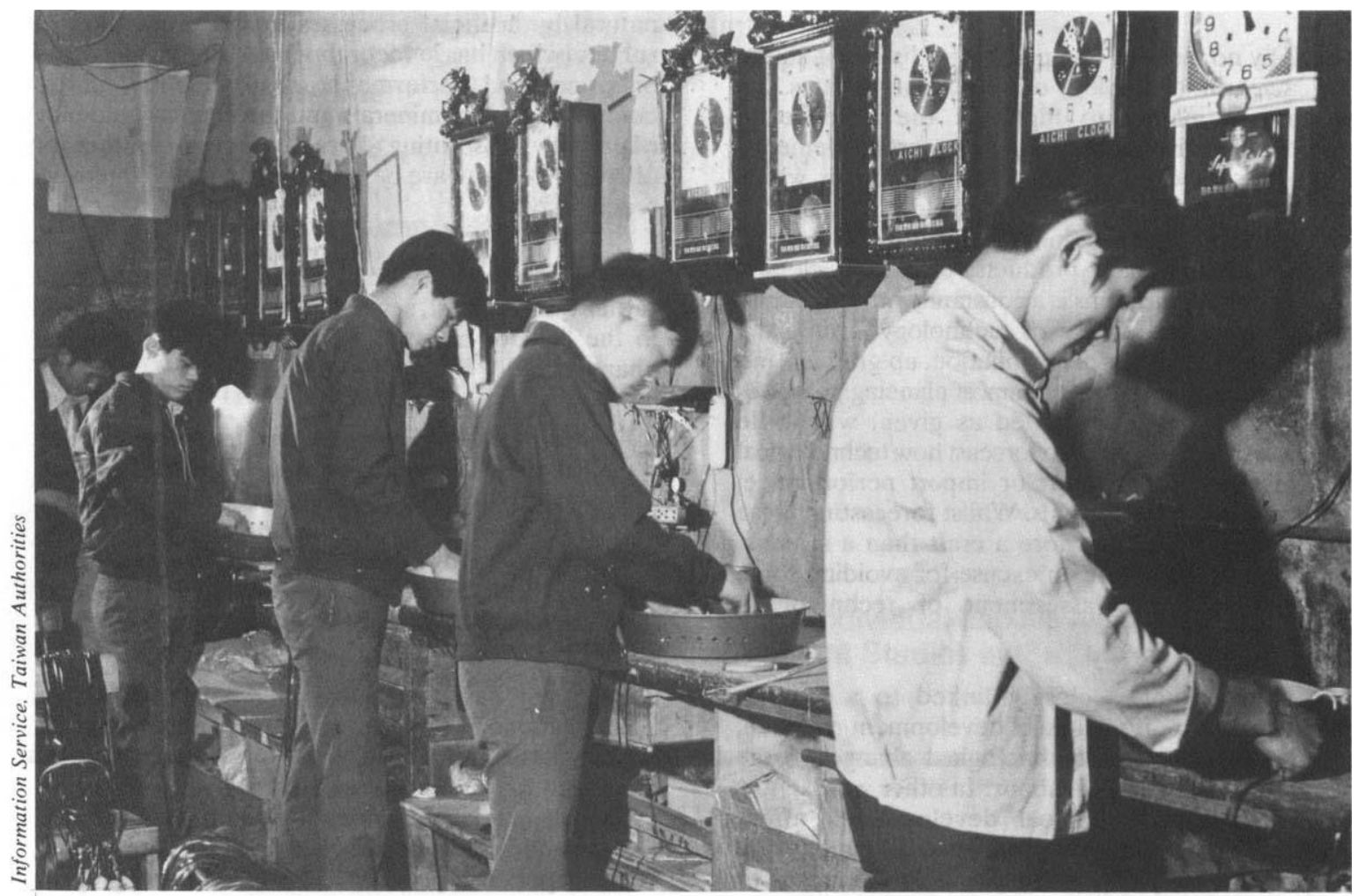

Labour intensive assembly of non-electronic clocks and watches. 
However it does not adequately consider the interaction between mature, semi-mature and advanced technologies. A mature technology could receive a substantial shot in the arm by developments in other, apparently unrelated areas of technologies, and acquire a new dynamism. For example, despite considerable talk, and work, on the 'readjustment' of the industrial structure of the developed countries, they remain the most important steel producers, ship-builders, carmanufacturers and even textile producers. These industries were thought to be natural candidates to go 'South', but through innovation in processes and products some have remained viable in high-wage economies. Many factors enter into play here, the most significant being the changing technological profile of traditional industries. This shift in technological profile does not only diminish the importance of direct labour cost in total manufacturing costs but also permits a chain of improvements in terms of quality, turn-around-time, customer service, stock management, office productivity and so on. In some cases, an improvement in the 'customer service' content of a given product is far more important than its actual manufacturing cost.

In addition, in some areas, market fragmentation (a characteristic of high income markets) is accompanied by specialisation with a heavy technological content. A good example here is in the electronics sector where in the area of memories or microprocessors one generation (for most applications) replaces rather than overlaps another. For instance, 4 bit microprocessors represented 100 per cent of the world microprocessor market in 1972, 23 per cent in 1980 and will account for only six per cent in 1985. (Projections of Creative Strategies International 1981.) The situation is similar for memories, with a new generation replacing the old in cycles of about eight years covering first introduction, peak and obsolescence.

Thus it is only natural that as markets grow so do the number of specialised niches. These products niches need to be highly specialised in order to offer features which truly justify their existence. In electronics again, success in these specialised sub-markets is conditioned by high technology content rather than because firms concetrate on stable products, and this occurs in both products (eg Uncommitted Logic Arrays) and processes (eg equipment). Although it is not possible to generalise from the experience of one sector, one should bear in mind that what is important about electronics is not just changes in the industry itself, but the fact that it is becoming a convergence industry. It is indispensable for a growing number of sectors' activities and services in which the content and format of information flows are changing. The entire industrial and service structure is thus moving toward a higher technological profile, with an ever-increasing emphasis on streamlining the production of software through the use of more firmware (which writes software into electronic components) and increasing modularity. These in turn, will accelerate the process of change.

\section{The context of current technological change}

The wider context in which current change takes place is one of slow growth, and there are no signs that this will change in the forese eable future. Under these types of conditions, two effects are relevant to this discussion. The first is that slow growth encourages, or in some cases, forces innovation in order to optimise the use of resources-thus the investment rationale is much more cost-drive than growth-driven. This is not to say that slow growth is the cause of an upsurge in innovation which as a process is far more complex than that. What it does mean is that the general conditions are more conducive to innovations (and their diffusion) than to increased production with stable technologies and products. The second consequence of low growth is greater competition, particularly on an international scale, which in turn creates political conditions for re-adjustment.

The globalisation of competition, particularly among multinational companies, and the upsurge of innovation constitutes a mixture which is increasingly conditioning the international division of labour. For instance, the nature of current technological change, especially information technology in its broader sense, deals with an area which by and large has remained unchanged since the 19th century, namely the office. The increase in office productivity or the streamlining of administrative activities to reduce 'overhead' cost is essential if companies are going to remain competitive. This shift in the way information is conceptualised opens completely new avenues that need to be explored. The transition of information from a purely organisational and cultural resource towards considering it as an economic resource implies that growing attention will be paid to the 'information intensity' of goods and services as a feature of the structure of developed societies. This also implies the rationalisation of 'information activities' as happened in previous epochs with regard to manufacturing and agricultural work.

\section{Some general features of contemporary technological change}

In the context described above, some general features of current technological developments can be tentatively foreseen. These generalisations are intended to contribute towards conceptualising the nature of current change, and they are inevitably, at this early stage, tentative in nature. Three categories will be 
mentioned here: the importance of science, the increasing dependence of production on capital, and the changing nature of information. In the final section we will discuss them in relation to the electronics sector.

\section{a) The importance of science}

One of the salient features of current and impending technological change is that its origin and early developments have been based on basic scientific research. This is true for semiconductor technology, biotechnology and is also becoming evident with regard to developments in materials-technology [see Braun and MacDonald 1978; Metropolis et al 1980; Editors of Electronics 1981; Gros et al 1979; Congress of the United States 1981]. As the theoretical content of technology grows, so does the skill mix required to absorb and develop technology. At the same time comparative advantages are conditioned by the science/technology endowment of a given country. In this sense, comparative advantages are deriving more from human activity and organisation than from nature (eg raw materials). In other words, production of goods and services is becoming more geographically independent as technology progresses.

These developments in the field of technology have another important characteristic which is relevant to our discussion - the need for sinergy. Today an innovation is seldom the result of developments in a single field. On the contrary, it tends to be a composite of many disciplines, some coming from seemingly unrelated areas. Examples of this type of sinergy are developments in genetic engineering which would not have been possible without computers; whilst development in computing would not have been possible without important breakthroughs in crystallography, metallurgy, and many other areas.

Consequently technology and its transfer is increasingly dependent on what is loosely called intangible knowledge'. This type of knowledge is not necessarily embodied in individuals but is rather the result of organisational systems and interaction. Two examples which have been clearly identified come to mind. The first is in the semiconductor industry where the use of patents, although normally practised, is not of great strategic value to companies. The industry relies much more heavily on trade secrets and a form of 'organisational knowledge' [Sterling, Hobe Corporation 1978; Kaplinsky 1982]. The high mobility of personnel in the industry, especially the transfer of entire teams, constitutes a more direct problem to companies than the infringement of patents. The second example is sof tware which is in many cases not patented precisely in order to avoid disclosure of information that would make it easy to copy. In the field of genetic engineering a similar process seems to be taking place as research in this area moves from academia to industry.

Due to the elements mentioned we encounter two important implications for the international division of labour. The first is that the growing theoretical content of technology makes its transfer difficult, given the techno-scientific infrastructure of most developing countries. The second is the increasing 'embodiment' of technology into goods and services. This is due to the growing importance of intangible knowledge' and the incorporation of functions and features into products and equipment. For instance, when precision mechanical components are replaced by electronic devices (eg watches, instruments, etc) this process of embodiment of technology takes place since functions performed in the past by separate elements are combined in a single circuit which in itself is a system rather than a component.

The trend towards systems rather than discrete components makes the absorption of technology by stages or parts (explicit in the concept of unpackaging technology) more difficult. At the same time, because of technological and commercial pressures, manufacturers of all kinds are moving towards total systems, with the service component incorporated. A well known example here has been the 'turn-key plants' in manufacturing, but one could add transport, banking and manufacturing systems. The trend is towards integration, which has partly been made possible by the characteristics and economy of information technology and microelectronics.

\section{b) The dependence of production on capital}

The second main feature is that production is increasingly the result of capital. This general statement, which describes a long historical trend, needs some refinement. Historically, the best example is agriculture, which through capital intensive labour- and landsaving technology, increased productivity tremendously over time. The developed countries are today the largest producers of agricultural goods, with only a fraction of their popualtion employed in the sector (typically, between three and ten per cent of the working population).

The diffusion of any technology is dependent on its factor-saving characteristics - whether labour, capital, materials, time or a combination of all of these. For our purpose one aspect is of particular importance here, and this is the labour-saving effect or, in other words, the decreasing importance of direct labour cost in total manufacturing and business cost. The debate in this topic in the last few years has been massive, and consensus seems to exist on one point at least that while there are labour saving effects at some 
levels, particularly in unskilled and semi-skilled manufacturing activities, at the same time there has been an increased demand for skilled labour in design, $\mathrm{R}$ and $\mathrm{D}$ and knowledge-intensive activities. This is only natural since automation at this stage of its development is increasingly dependent upon these skills.

Without entering too deeply into the debate on the choice of techniques, what is of interest from the point of view of the international division of labour is that the labour saving bias of new technology precisely affects jobs which were thought to be most suitable for developing countries. This argument has often caused confusion, as if one were suggesting that labour cost is, or will be irrelevant, or that developing countries will become a sort of industrial desert. Three points should be made in this respect and some of them I hope to illustrate later through the example of the semiconductor industry. The first is that the term 'developing country' is short-hand for a tremendous variety of structures and development strategies. Thus, for countries with large internal markets (eg India, Brazil, Mexico) the effects of technology, and also their capacity to negotiate technology, is quite different from those with small markets or with an export-led development strategy. Second, research on the international division of labour, particularly in relation to the future of off-shore activities, has concentrated to a great extent on the relocation of plants because of the nature of technology. These types of activity involved few countries and few industrial sectors and the conclusions do not necessarily apply to the impact of technology in countries that have followed a different strategy, nor with regard to the individual sectors which were considered to be potential candidates to relocate in the 'South'. This points out the need for further research, but at the same time it should be clearly recognised that what happens is that labour cost becomes less of a constraint for production (in as much as the relative share of fixed-costs increase, in some cases substantially) and not because labour costs become irrelevant.

What this says is that the industrialisation alternatives for developing countries are becoming narrower and more complex. A third clarification refers to changes in markets as producers emphasise quality of products and innovation in order to compete in conditions of low growth. This in itself changes the requirements of production in terms of the type and skill-mix required. The changes in markets should not be underestimated, especially because they shorten the time span of individual product cycles, often forcing structural changes and specialisation in industry.

\section{c) Information}

A final general feature, which I do not propose to go into in detail here, is the growing importance of information as an economic resource, or the growing 'information intensity' of goods and services. The fact that electronic components, computers and, increasingly, telecommunications operate in the same language opens the way to a new type of social and economic infrastructure. There are essentially two trends forcing changes here. One is the ever-growing amount of information that needs to be collected, processed and retrieved, and the other is changes in technology which reduce the cost and increase the reliability and flexibility of processing information.

This process, which has been called 'informatisation' of society, is one which simply accounts for the fact that in order to produce a good or a service, much more information is required than in the past. This is because research intensity, coordination, marketing and other business needs with a heavy information content, are growing. From the point of view of the international division of labour at least two aspects are of great importance here.

The first refers to the process of rationalisation and automation of office work which will increase overall business productivity while augmenting fixed cost. In this respect little is known about how these processes rapidly underway in the developed countries will affect comparative advantages. Whilst in the past technology has essentially been oriented to production processes, whether in the primary or secondary sector, what is now required is a broader view which recognises that productivity growth is increasingly dependent on information and clerical activities. In many industries already, the majority of the labour force is employed in clerical and professional activities rather than on the 'shop-floor'. The economic availability of information technology now makes it possible to address systematically the question of office productivity. Changes in this area, by altering relative factor cost, will undoubtedly affect location and investment patterns.

The second aspect, of more immediate concern, is the concentration of 'information intensive' sectors in some developed countries. These sectors involve time sharing services, consulting, data bases and banks, design processes, $R$ and $D$, software developments and other types of services (eg banking). This is not only a question of concentration of service activities (in the 'tertiary sector' sense) but more importantly, concerns an increase in the service content of material production. In many areas it is no longer feasible merely to produce an item-it is also necessary to provide with it after sales service, repair, maintenance and the compatibility for upgrading.

The case of software is an example here. In the total cost of software over its entire product cycle, 
maintenance constitutes $60-80$ per cent of total cost, and development 20-40 per cent. For maintenance, however, a vast service network is required with a close contact with end-users. The bulk of the revenue during the cycle of the product software is then the 'service' of it rather than the original production. (This of course is not applicable to packaged software or dedicated machines.) Similar changes are forecast in the case of programmable machine tools where the provision of software, its maintenance and a connection with 'machining data bases' (MDB) or 'computer aided design' (CAD) systems might be essential. As has happened with computers, it is likely that the overall cost of manufacturing tools and machinery will be more dependent on the 'service' content of the goods rather than on the 'hardware'. Therefore, the process of concentration of 'information intensive' activities involves many old and new types of services as well as the 'informatisation' of material goods. With the changing technological profile of productive activities the gap in this area between developed and developing countries is most likely to increase if judged only by the projected expenditure in establishing informatics infrastructures. The issues involved in this area are extremely broad, ranging from questions of telecommunication agreements and use of satellites to the economically and politically difficult issue of Transborder Data Flow.

Some elements of the three main aspects mentioned above can be explored through the specific case of the semiconductor industry, which provides an important illustrative case of these trends due to its heavy technological content and the fact that it has been most extensively used in assembly plants in developing countries. At the same time progress in semiconductors is deeply conditioning trends in other industries, ranging from consumer and professional electronics to heavy capital goods. The intention in the next section is not to explore all aspects conditioning industry behaviour, but only those specifically affecting location and investment patterns. For reasons of space, one aspect of great interest in the case of this industry, namely technological behaviour, will be omitted.

\section{The semiconductor industry}

From the point of view of investment and location the main factors conditioning behaviour in the semiconductor industry are company structure, firm strategy and the characteristics of the national economic system. This statement is applicable to semi-captive and merchant (selling in the open market) producers rather than captive producers which operate with different rationales (ie IBM or Western Electric). In terms of the structure of the industry some important changes have taken place, particularly in the US industry since 1977. While in the early 1970s the industry was characterised by the existence of independent, technologically innovative, big and small producers, today the archetype seems to be vertically integrated companies, and the independent producers have become less prominent. By contrast, the five large Japanese semiconductor producers and the two largest European ones have always been vertically integrated. Thus the USA, where the most innovative companies have been based, has been the exception. But now, even there, most companies have developed corporate links or are wholly-owned subsidiaries of large corporations. For instance, if one considers even the US merchant market (ie those selling products in the open market) by the equity characteristics of producers, it looks as follows:

Independent (Texas Instruments, Motorola, National Semiconductors, Intel)

Subsidiaries and divisions of major corporations

Majority control by major corporations

Minority control by major corporations

Others (mainly small independent producers)

* based on 1979 sales figures

If we consider the overall activities of the 'big league' firms we would note that some of them have themselves become vertically integrated corporations. Thus, unlike National Semiconductors and Intel (with over 70 per cent of their sales concentrated in semiconductors), the semiconductor operations of Texas Instruments and Motorola represent only 47 and 37 per cent respectively of total sales.

The reasons for this development in the industry are related to three main factors discussed above, namely capital requirements, cost of $R$ and $D$ and access to technology [Rada 1982]. This change in structure is accompanied by a growing number of captive and semi-captive production facilities, especially for integrated circuits. Automobile manufacturers, camera producers, office equipment companies and many others are recognising the importance of vertical integration as a way of ensuring supplies and also of distinguishing their final products in the market-place by tailoring electronic components to their own needs and systems. A sign of this trend is that in the US, 23 captive facilities were established in 1970 and 61 in 1980 [Bojert and Vieber 1981 ].

Thus the 'archetype' semiconductor company is increasingly becoming a vertically integrated one as technological and economic pressures force the producers of components into the production of 
systems, and systems producers into the manufacture of components. At the same time a risk-averting strategy is pursued to maintain a level of innovation and technological tie-ups that allow companies to quickly 'ride' the learning curve and defeat or neutralise the natural economies of scale of very large vertically integrated TNCs.

But whilst the above may be an accurate reflection of the mass production merchant market, it is also true that as the market expands so do the number of niches. So one can expect numerous new entries and success stories in specialised circuits and equipment, and also the subcontracting to highly specialised companies of part of the production process.

But in this industry, perhaps more than any other, market share needs to be heavily qualified by two considerations. The first is by market segment where, for example, in the case of microprocessors, Intel is on top, mastering the most complex technology. The second is what one might call 'technology share' which occurs due to second sourcing. For example, American Micro Devices (AMD) which only has about two per cent of the total US semiconductor market, has a much larger presence in integrated circuits. In the 4bit microprocessor segment, its direct share was 57 per cent (by volume), but if we consider indirect shares, AMD accounts for 70 per cent (by volume) of the market due to the fact that 13 per cent is second sourced (via licences) to companies such as Fairchild, Hitachi, NEC, Philips and Diemens. Siemens in turn owns about 20 per cent of AMD (Creative Strategies International 1981).

Second sourcing, equity participation, technology tieups and joint research efforts all suggest that to look at the main actors from any particular angle is necessarily a partial view, and the greater the segmentation of the market, the more complex the analysis of actors will become. In addition, the conditions under which the different companies operate varies. For instance, the largest portion of equity in Japanese companies is held by financial institutions or other companies, while individuals hold a relatively low percentage as compared with US companies. Furthermore the Japanese industry's vertical structure affects the cost of capital because it allows profits from one division to be used to finance investment in another. The result of this structure is that Japanese semiconductor companies employ significantly higher debt ratios than US semiconductor companies. Typically, they maintain debt-to-capital ratios of $60-70$ per cent while US companies range between 16 and 18 per cent. Consequently the cost of capital to Japanese semiconductor companies is significantly lower than that of the US companies, and this is largely a result of the higher debt ratios employed by the Japanese. As a result their required rate of return on investment is lower than those of US companies. Thus, in the period $1977-79$, the typical US electronic company earned 16.3 per cent on capital employed, whilst in the same period the Japanese companies earned 7.5 per cent on capital. (Rate of return for capital is defined here as net operating profits after taxes as a percentage of average total debt and equity capital employed.) As a result of these elements, Japanese companies can accept lower profit margins, lower rates of return on capital and a lower cost of capital. Under these conditions the cost pressures on Japanese producers are different and to a large extent this explains their emphasis on product quality through rapid automation, which requires large outlays of capital. Thus if in the 1970s the recipe for success was volume/yields, today it is volume/yields/quality and in order to achieve it more complex, expensive and automatic plants are required.

The Japanese have come to be noted for the high degree of automation of their assembly process, with the level of cleanliness approaching that of wafer processing. They tend to rely more on automatic equipment than on in-line inspection. Many changes are also taking place on types of materials and packages in an effort to increase quality by merging together production and design engineering. The approach is 'hands-off' whenever possible. However it is worth noting that the pace of automation varies for different companies and products. For memory devices, with high margins and a massive market, the trend to automation is strong. For other more expensive and low margin devices, the pace is slower, and packaging and assembling tend to be a relatively smaller proportion of the total cost.

Now, extensive use of automatic equipment and expensive capital intensive plants allow producers to reduce-or at least not expand-off-shore assembly in developing countries, which in the past has utilised relatively labour-intensive technology. In addition the cost of operating capital intensive plants tends to be relatively similar, independent of location. This points to one of the notable differences between Japanese and US producers, which concerns the use of offshore plants as a major source of capacity. The data suggest that Japanese firms do not utilise off-shore manufacturing to support a significant percentage of output (both by volume and value). Nevertheless partly due to their use of automated techniques, they are able to compete successfully on price.

The reluctance of the Japanese to rely on off-shore plants is due to the belief that quality cannot be assured in labour-intensive production. Their latest significant off-shore investments are in the USA and Europe mainly because of the need to have access to 
markets and to avoid trade friction. US companies operating under very different conditions are forced to follow a strategy which tends to maximise shortterm profits. Thus the constraints on cost are very different, especially in terms of capital investment in fully automated plants. In addition US custom regulations (items 806.00 and 807.30 ) have encouraged the use of off-shore facilities. These regulations only tax foreign materials, and value added abroad to imported products. However, despite the upgrading of off-shore plants (eg, adding testing in some of them) the value added outside the US has been consistently declining, in the case of integrated circuits from 57 per cent in 1974, to 39 per cent in 1978 . This is due to the increasing value of the parts of devices produced in the USA [US International Trade Commission 1979:14|.

A comparison between the USA and Japan shows the following:

\section{Approximate off-shore production of US and Japanese semiconductor companies as percentage of the value of total domestic production}

$\begin{array}{lrr} & 1978 & 1979 \\ \text { Japan } & 3 & 3 \\ \text { USA } & 37 & \mathrm{na}^{1}\end{array}$

Source: based on data from the Bank of Asia, The Semiconductor Industry in Japan. Hong Kong 1980, and US International Trade Commission, Competitive Factors Influencing World Trade in Semiconductors, Washington 1979.

${ }^{1} \mathrm{~A}$ fair assumption would be that the percentage remains the same.

By far the largest number of off-shore plants belong to US producers. Thus of 112 off-shore plants in 1981 assembling semiconductors, 69 per cent belong to US companies, 12 per cent to European and 19 per cent to Japanese producers.

In terms of labour-cost, an item of particular importance to US producers, wage differentials $v i s-a$-vis off-shore facilities remain large-typically a ratio of 1:4. Nevertheless, if labour cost were the prime consideration for choosing, fabricating and assembling sites, many companies would have moved to lower wage countries as relative wage costs have risen in some of the more successful NICs. However, although some movement has taken place, by and large the industry remains in the areas of original investment. Hence, large producers have relatively few plants in very low wage countries such as Thailand 5 , Indonesia 3 and India 3 . By contrast they have 16 plants in
Singapore, which is one of the most expensive countries in terms of wages for assembling-type operations. However it should be emphasised here that labour cost has never been the only consideration for choosing off-shore sites. There are many other elements including infrastructure, political considerations, tax and capital incentives and conditions for foreign investment.

These impending changes in the structure of the industry have not entirely sunk in yet, but the process of rationalisation and streamlining is likely to accelerate in the next few years. The consequence of this rationalisation will be to affect off-shore locations, levels of employment, increased vertical integration and capital intensity, and last but not least, the industry will become more fiercely competitive. For example, Siemens is slowly digesting its acquisitions and has overlapping off-shore plants with Litronix (with which it has recently formed equity links) in Singapore and Malaysia, while a Litronix plant in Mauritius has been closed. General Electric overlaps with an Intersil plant (which it has just purchased) in Singapore. The same pattern is applicable to many other companies in terms of plants, sales, marketing structures, and, of course, $R$ and $D$.

In the short run, especially for smaller producers, offshore locations (particularly in Asia) are attractive, since they are far less capital intensive than highly automated domestic plants. For those with heavy commitments overseas, such as Fairchild, automation of some of these stages of existing off-shore operations are only rational. But at the same time we have seen in the last year the birth of specialised assembly companies on-shore (eg California) with highly automated lines, lower turnaround time and greater proximity to customers.

Whilst smaller companies and new entrants might turn to subcontracting assembling operations off-shore, as well as on-shore, rather than overstretch their managerial and financial resources with wholly-owned operations, the fact is that the larger the company and the more vertically integrated, (which, as we have argued, appears to be the trend) the less the use of offshore plants in terms of numbers as well as size. Thus for similar value for semiconductor sales NEC has three off-shore plants and National Semiconductors six: Hitachi two and Fairchild seven; Philips two and Motorola eight. As fixed costs become larger as a proportion of total cost and the value added in semiconductor manufacture operations (as opposed to assembly) grows, we shall see an acceleration of the rationalisation in the present distribution of plans. In addition, as quality becomes crucial for competitiveness, assembly will change substantially with automation and the use of clean rooms. At this point fully integrated 
manufacturing plants will become more economical than the fragmentation of production.

Three elements are, then, conditioning current changes in semiconductors. The first is the alteration of firm structure, due to the increasing capital and $R$ and $D$ needs, including basic research, leading towards larger, vertical integrated companies. Secondly, automation is increasing the fixed cost of production and changing the skill-mix in plants. This diminishes the relative importance of low-wage direct labour cost. Thirdly, and closely related to the second point, is the drive for quality, which is forcing automation and the use of highly capital-intensive plants.

Other elements that condition the use of off-shore plants, eg tax and capital incentives, are also decreasing in importance as many developed countries have put into effect plans and incentives to encourage the electronics industry and which, in some cases, might neutralise, in relative terms, the advantage of offshore locations. A case in point here is Scotland and France, both of which have been successful in either attracting foreign investment or developing technological ties and cross-licence agreements. The largest investments in integrated circuits (outside the companies' own countries) have taken place in Scotland in the last three years.

\section{Conclusion}

All the elements discussed in this article can be summarised by one main conclusion. This is, that for development studies, whether in the economic, social and political field or in specific areas of human resources and transfer of technology a very dynamic view of technological change should be incorporated. The complexity of the issues involved makes it necessary to take a transdisciplinary appraoch to research and to begin questioning very systematically some of the basic assumptions of commonly professed development theories. Prospective technological assessment should become a central element in economic studies and planning, and should deserve far more attention than has been the case so far, especially in the context of work on development.

\section{References}

Bojert, H. and F. Vieber, 1981, Wafer Fabrication in the 1980s, Dataquest

Braun, E. and S. MacDonald, 1978, Revolution in Miniature, Cambidge University Press

Congress of the United States, Office of Technology Assessment (OTA), 1981, 'Impacts of Applied Genetics: MicroOrganisms. Plants and Animals', Appendix I-B

Editors of Electronics, 1981, An Age of Innovation: the World Electronics 1930-2000, McGraw-Hill Publications Co

Gros, F. et al, 1979, Sciences de la Vie et Société, La Documentation Francaise, Paris

Kaplinsky, R., 1982, The Impact of Electronics on the Inter national Division of Labour - the illustrative case of computer aided design, Frances Pinter, London

Landes, D., 1976, The Unbound Prometheus: technological change and industrial development in Western Europe from 1750 to the present, Cambridge University Press

Metropolis, N. et al, 1980, A History of Computing in the Twentieth Centuny, Academic Press

Rada, J., 1982, Structure and Behaviour of the International Semiconductor Industry, UNCTC, New York

Sterling, Hobe Corporation, 1978, International Transfer of Semiconductor Technology, Report prepared for the US Dept of Labor

Stern, J., 1980, International Structural Differences in Financing in Semiconductor Industry Association (SIA); an American response to the foreign industrial challenge in high technology industries, California

US International Trade Commission 1979, Competitive Factors Influencing World Trade in Integrated Circuits, Washington 